\title{
FATORES DE RISCO INDUSTRIAL CAUSADOS POR DIFERENTES PERCEPÇÕES DE CORES DEVIDO À DIFERENÇA DE ILUMINANTES
}

\section{INDUSTRIAL RISK FACTORS CAUSED BY DIFFERENT COLOR PERCEPTION DUE TO LIGHTING DIFFERENCES}

\author{
Andrea Rozendo M. dos Santos, MSc \\ Programa de Pós-Graduação em Engenharia Mecânica \\ Universidade Federal Fluminense \\ R. Passo da Pátria, 156, Niterói - RJ \\ Fabiana Rodrigues Leta, DSc \\ Programa de Pós-Graduação em Engenharia Mecânica \\ Laboratório de Metrologia Dimensional e Computacional \\ Universidade Federal Fluminense \\ R. Passo da Pátria, 156, Niterói - RJ, Tel: 021-2629-5460 \\ E-mail: fabiana@lmdc.uff.br, fabiana@vm.uff.br \\ Márcia Pimenta Velloso, DSc \\ Programa de Pós-Graduação em Engenharia Civil \\ Laboratório de Metrologia Dimensional e Computacional \\ Universidade Federal Fluminense \\ R. Passo da Pátria, 156, Niterói - RJ, Tel: 021-2629-5575 \\ E-mail: marcia@pimentavelloso.org
}

\section{RESUMO}

Este artigo apresenta uma reflexão sobre os fatores de risco industrial decorrentes da percepção visual humana, com embasamento empírico, de como a percepção de cores no ambiente industrial e laboratorial exerce influência direta na qualidade dos serviços e na segurança dos indivíduos que freqüentam tais instalações. Estes ambientes possuem tubulações e cilindros, cujas cores têm por objetivo a identificação de produtos e seu grau de periculosidade. O usuário, comum ou treinado, em muitas situações não compreende tais informações, seja por mudança perceptual da cor em função da iluminação ou ainda por que as cores percebidas não transmitem corretamente estas informações. Este artigo tem como 
objetivo principal levantar uma discussão sobre os conceitos mais relevantes envolvidos na percepção de cores e nos iluminantes, bem como iniciar uma reflexão sobre as normas técnicas usualmente adotadas, alertando os órgãos responsáveis sobre a relevância do tema. A cor é o atributo mais evidente de produtos, anúncios e sinalizações, e por esta razão deve ser criteriosamente utilizada, em especial em ambientes nos quais os riscos são evidenciados através da mesma.

PALAVRAS-CHAVE: fator de risco, iluminação, cor.

\begin{abstract}
This work presents a discussion about risk factors involving changes of color perception depending on lighting source. It is based on empirical study of the color perception in the industrial environments. It influences in the quality of the services and in the individuals' workers safety. In these environments there are piping and cylinders painted with different colors in order to transmit the kind of gas/fluid inside and, many times, to transmit danger information to the user. Ordinary and trained people many times don't realize this information. It occurs because of the color perception change by the lighting and also because of the inadequate use of the color to transmit the information. We have, as main objective to make a review of the existing principal aspects and start a discussion about the standards and effective laws in the country, alerting the responsible organs that the correct identification of the colors in the industries is fundamental. Color is an important attributed in products, announcements and signs. For that reason, it must be used carefully, particularly in environments where it is used to call attention to risks and danger.
\end{abstract}

KEY-WORDS: risk, color, lighting.

\title{
1- INTRODUÇÃO
}

A curiosidade em relação às cores utilizadas nas instalações, equipamentos, uniformes, sinais de advertência e em tantas outras aplicações no ambiente industrial, direcionou o foco desta pesquisa para a importância da percepção de cores nas indústrias, especialmente no que tange a questões de segurança.

Observando-se instalações laboratoriais e industriais, nota-se a presença de tubulações e cilindros coloridos, contendo gases de diversas composições, porém, sem nenhuma identificação de quais seriam esses gases. Imaginando uma situação de emergência, como um incêndio, por exemplo, uma questão surge: visitantes, pessoal de manutenção e limpeza, enfim, indivíduos leigos quanto às normas de utilização de cores, saberiam dizer quais elementos representam maior perigo em casos de incêndios ou explosões?

Existe uma relação entre as cores dos cilindros e os tipos de gases contidos neles, o 
mesmo ocorre em tubulações industriais, entretanto, pode-se constatar que uma simples troca de lâmpada nos laboratórios altera as cores dos cilindros, que se tornam confusas e indistintas. Assim, o interesse inicial pelo tema, tornourse uma preocupação.

Nas figuras seguintes têm-se exemplos de cilindros e mangueiras que, seja por má conservação ou por iluminações distintas, podem gerar situações de risco. Na figura 1.1, pode-se observar como é difícil distinguir as cores dos cilindros em função do envelhecimento das tintas coloridas aplicadas.
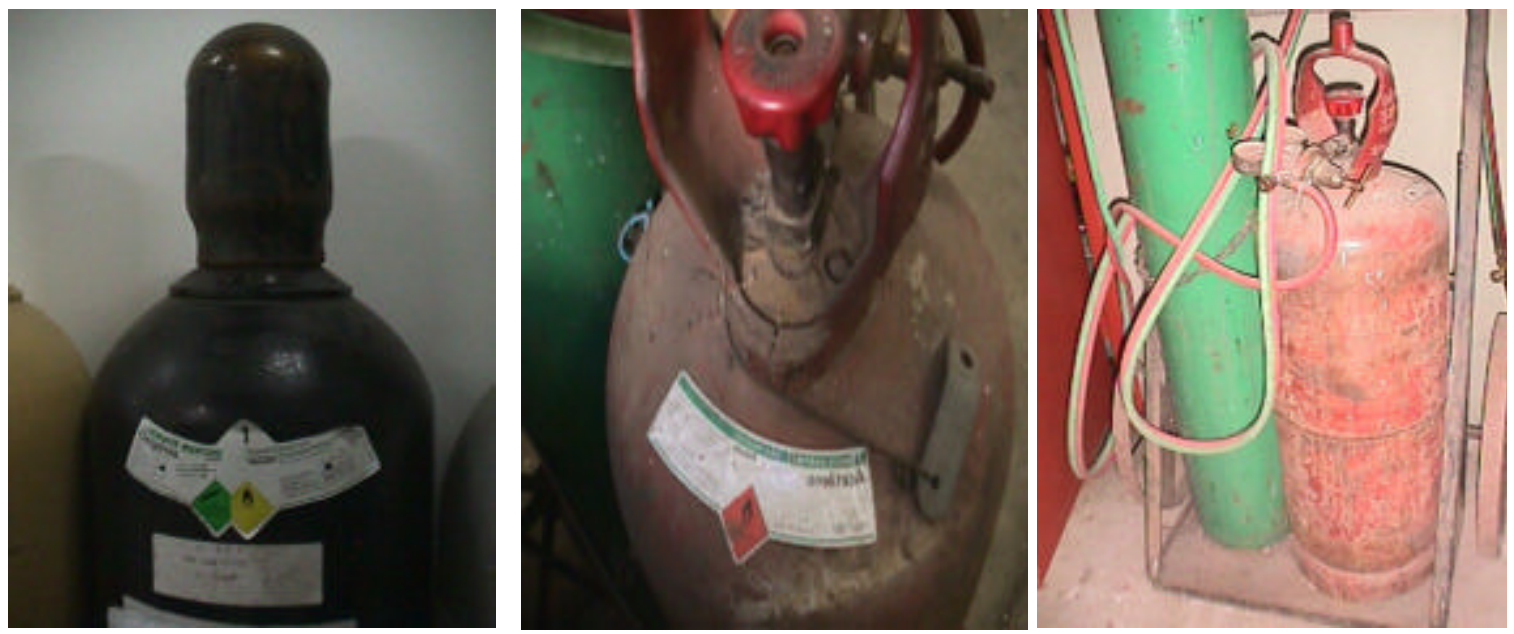

Figura 1.1-Cilindros com pinturas envelhecidas.

Na figura 1.2 pode-se comparar duas situações em que a intensidade de luz altera significativamente a percepção das cores dos cilindros.
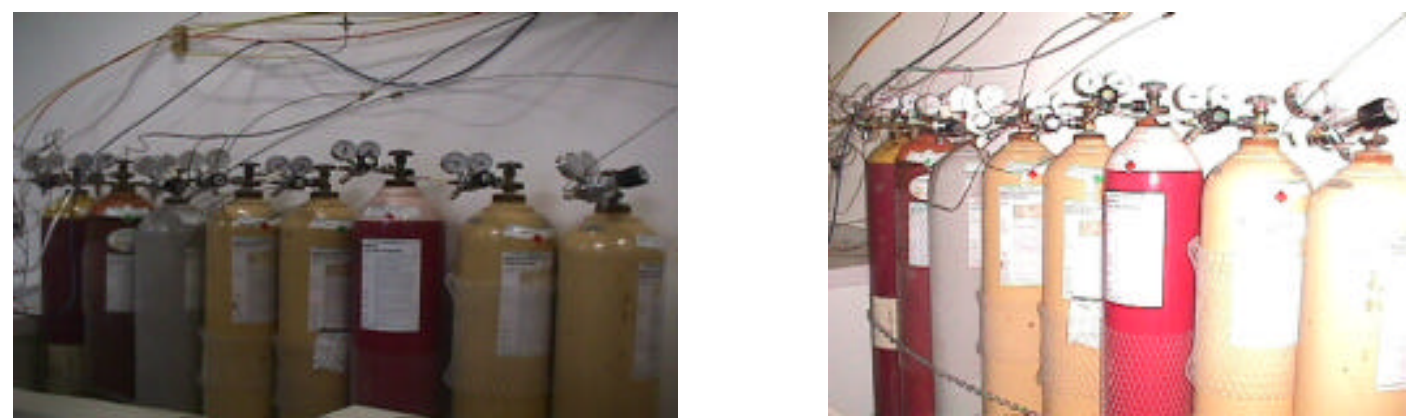

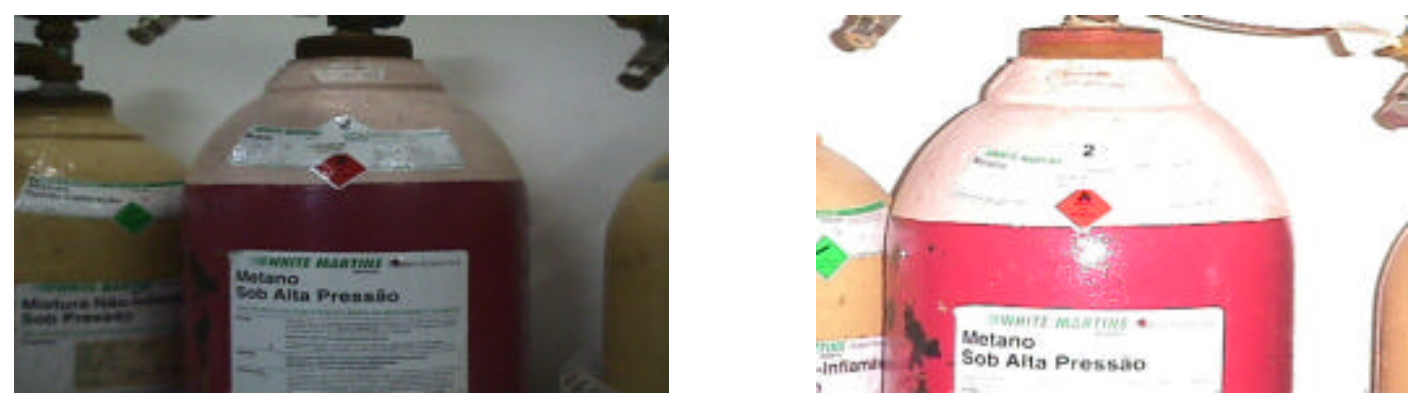

Figura 1.2 - Cilindros sujeitos a iluminantes diferentes.

Outra situação observada na Fig. 1.3 consiste no transformador que indica uma ligação dos fios marrom com azul, porém na imagem impressa a cor utilizada para representar o fio marrom é a cor vermelha. O problema é que no mesmo transformador existe o fio vermelho também, que se ligado ao fio azul acarreta um curto circuito.
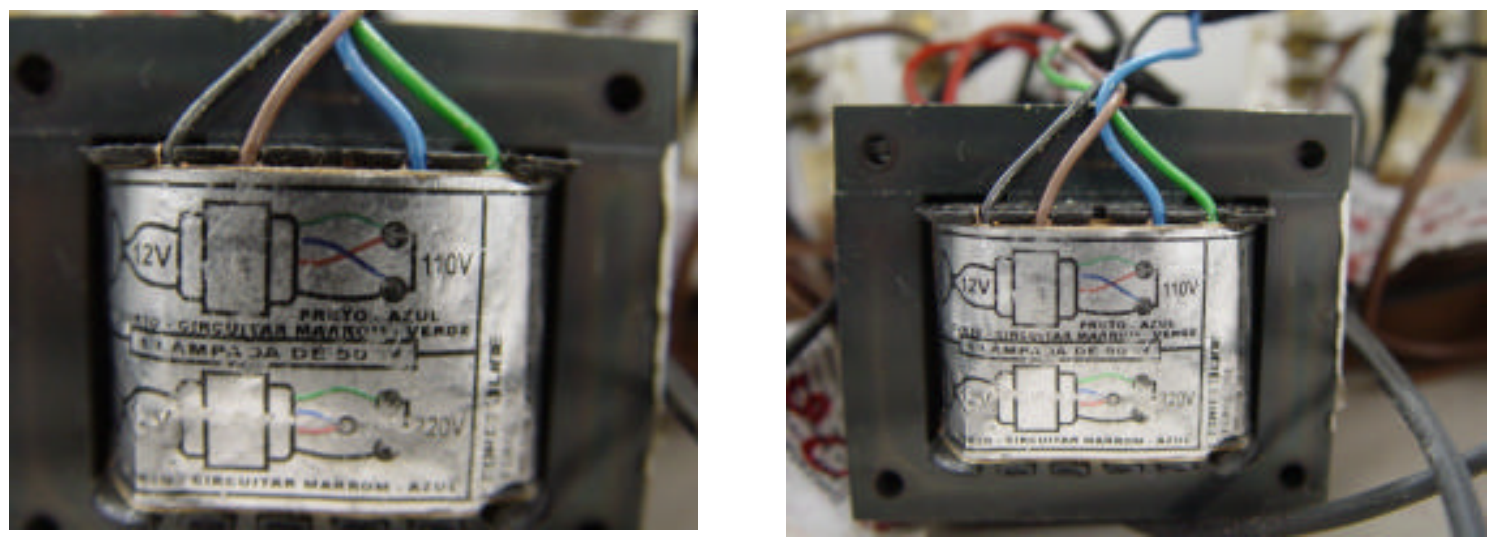

Figura 1.3 - Fotos de um transformador com fios coloridos.

O objetivo do presente trabalho é o de chamar a atenção das indústrias e órgãos regulamentadores da área de iluminação e cores sobre a necessidade da revisão das normas e leis vigentes no país. No Brasil, as normas ou recomendações relativas aos projetos de sistema de iluminação ainda não contemplam as novas tecnologias da área. Aos especialistas, resta adotar valores e métodos utilizados em outros países. Entretanto, tal procedimento acarreta muitas vezes contradições entre as normas adotadas e a lei brasileira.

O mercado técnico brasileiro, em permanente expansão, visando cada vez maior competitividade, deve atentar ao fato de que um sistema de iluminação engloba várias etapas no ciclo de qualidade, inclusive a de percepção de cores, que não deve ser desconhecida pelos responsáveis pelos projetos. As medidas adotadas pelo Brasil, como o Código de Defesa do Consumidor e as Normas de Gestão de Qualidade, mostram claramente que o país está aos 
poucos adquirindo a experiência dos países mais avançados. Chama-se a atenção para o Art. $8^{\circ}$ do Código de Defesa do Consumidor, onde menciona que: "Os produtos e serviços colocados no mercado de consumo não devem acarretar riscos à saúde ou à segurança dos consumidores" (Costa, 1998).

Produzir com qualidade não é uma tarefa fácil, mas, as normas e leis existentes, bem como as que estão por vir, procuram desenvolver esta mentalidade nas indústrias do país. $\mathrm{O}$ mais importante é que elas existem e os especialistas não podem alegar seu desconhecimento (dos Santos, 2003). Assim, uma das formas de atingir o objetivo da qualidade é realizar o trabalho com conhecimento de causa e com documentação adequada. Para tal, a associação entre centros de pesquisa, universidades e prestadores de serviço, podem permitir a instalação de sistemas apropriados à tarefa visual.

\section{2- COR E PERCEPÇÃO}

Existem questões aparentemente triviais cujas respostas são supostamente incontestáveis. Por exemplo: Qual a cor do céu? Quem é mais quente, o fogo ou o gelo? Agora observe essas mesmas perguntas formuladas de maneira diferente: Como se sabe qual é a cor do céu? Ou, como se sabe o quanto o fogo é mais quente que o gelo? Novamente as respostas são consideradas óbvias, pois, as pessoas vêem a cor do céu, sentem a temperatura da chama e do cubo de gelo. Enfim, as respostas partem imediatamente dos sentidos.

Acredita-se que se vemos um objeto é porque ele existe, e se ouvimos um som é porque algo ou alguém foi capaz de produzi-lo. E essa credibilidade nos nossos sentidos permite muitas vezes manter nossa integridade física, pois quando desviamos de um carro vindo em nossa direção, aceitamos as informações dos nossos olhos e ouvidos. Mas, a correspondência entre a percepção imediata e a realidade externa não é tão simples assim. A facilidade com que usamos os nossos sentidos, enxergando aparentemente através do simples ato de abrir os olhos, ou tocando algo apenas pressionando a pele contra o objeto em questão, se sobrepõe ao fato da percepção ser uma atividade extremamente sofisticada do cérebro. A percepção busca constantemente dados armazenados na memória, efetua uma série de classificações, comparações e decisões antes que qualquer dado seja transformado no que nossa consciência julgue ser real (Lida, 1995).

A sensação e a percepção são os primeiros processos complexos que ocorrem quando alguém inicia seu comportamento. Assim, a percepção não fornece um conhecimento direto 
do mundo, esse conhecimento é o produto final de vários processos. E muitos dos comportamentos dos seres humanos visam superar falhas da natureza dessas percepções.

A palavra cor é associada a três significados: cor psicofísica, cor objeto e cor percebida. A análise da cor psicofísica reduz-se à descrição da luz em termos de potência de radiação. A cor objeto é aquela refletida por um objeto quando este é iluminado por uma fonte de luz (e é esta cor que atingirá o sistema visual). E por cor percebida entende-se como sendo a percepção imediata que se tem do objeto, e será o resultado da interação de vários fatores complexos (Costa, 1998).

A cor está relacionada com uma banda estreita do espectro eletromagnético, mas, suficiente para servir de suporte à $80 \%$ da informação recebida pelo homem. A energia eletromagnética possui uma larga faixa de comprimentos de onda, variando desde frações mínimas de um centímetro até quilômetros de extensão. A seção do espectro eletromagnético que abrange a luz visível é muito pequena, e vai aproximadamente de 400 a $700 \mathrm{~nm}$ (1 nanometro $\left.=10^{-9} \mathrm{~m}\right)$. As variações de comprimentos de onda dentro desta faixa correspondem às cores da luz visível, conforme pode ser observado na figura 2.1 (Coren et al, 1979).

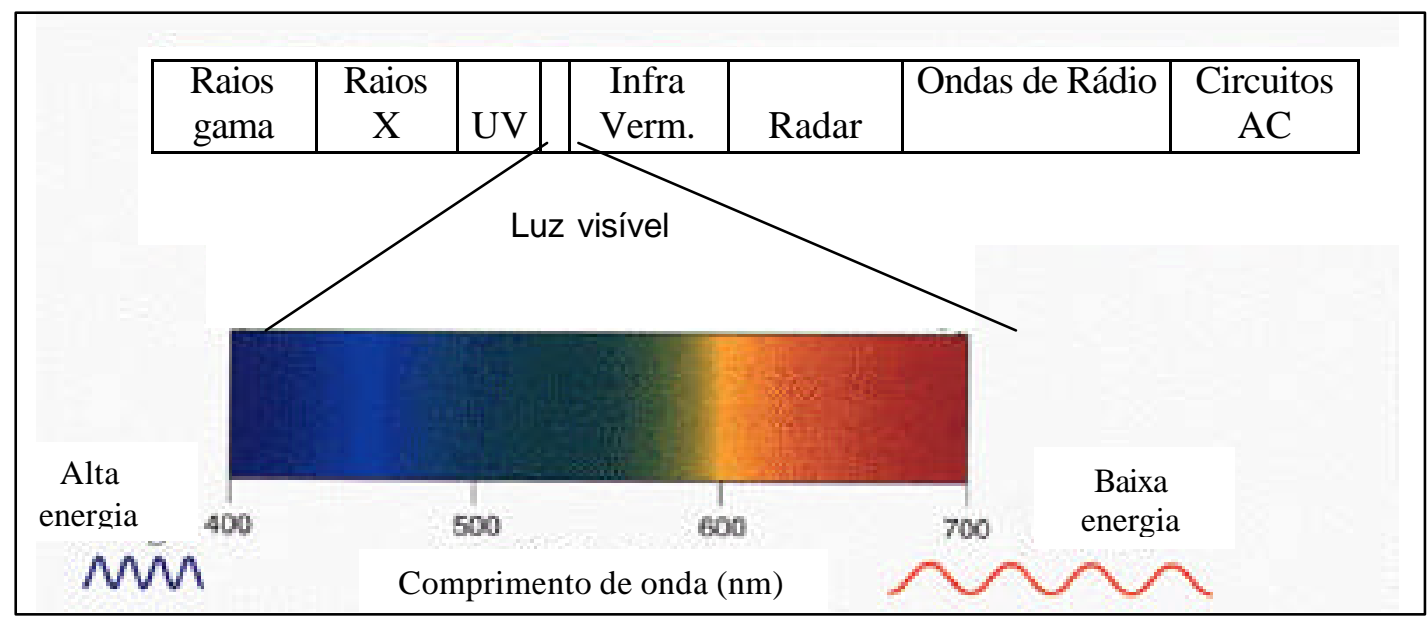

Figura 2.1 - Espectro eletromagnético.

O olho atua como um seletor sensível a uma faixa do espectro eletromagnético, diferindo de outros seletores pela dificuldade de mensuração por unidade física da sensação produzida pelo estímulo, pois, a regeneração dos elementos da retina processa-se logo após uma fração de segundos. A sensibilidade dos animais ao comprimento de onda varia bastante, por exemplo, muitos animais vertebrados noturnos não são sensíveis à luz de comprimento de onda longo, que os seres humanos vêem como o vermelho. Já alguns insetos são sensíveis a 
comprimentos de onda muito curtos, como a luz ultravioleta, invisível ao homem. Entretanto, a percepção da cor depende de muitos outros fatores além do seu comprimento de onda (Coren et al, 1979).

Observe que a idade da pessoa altera sua capacidade de percepção das cores. Não somente pelo fato de a lente cristalina do olho tornar-se amarelada ao longo dos anos, como veremos adiante, como também pelo fato do tempo deteriorar gradualmente a visão do azulamarelo. Fatores físicos, chamados de cromatopsias também geram perdas nos resultados de discriminação de cores. Existem várias doenças que podem ser incluídas aí. No caso da diabete, o sistema azul-amarelo perde bastante eficiência, enquanto o vermelho-verde parece inalterado (Coren et al, 1979).

Alguns outros fatores curiosos também alteram a percepção de cores. Por exemplo, a memória de cores tende a aumentar o brilho de nuances brilhantes, e tornar ainda mais escuras nuances escuras. A cultura é um outro fator marcante. Em línguas que possuem poucos termos para diferenciar as cores, os indivíduos não possuem a mesma habilidade para percebê-las que os povos que possuem nomes diferenciados para cada nuance (Coren et al, 1979).

A cor também é um ingrediente comum numa variedade de sinais, assim como em inúmeras situações que ocorrem no cotidiano. As cores são a fonte de informação básica em sinais de trânsito e em muitas sociedades tendemos a associar certas cores com eventos específicos. Enfim, é razoável considerarmos que a cor de um sinal é um dos fatores na sua interpretação.

\section{3- PROCESSOS SENSORIAS DA PERCEPÇÃO DA COR}

O reconhecimento que efetuamos através da visão implica na identificação da forma, do movimento e da cor.Quando se deseja estudar a percepção, o foco estará nas experiências conscientes dos objetos. Existem diversos estudos e abordagens para este mesmo tema, mas, com o intuito de facilitar a compreensão do estudo da sensação, ou dos processos sensoriais, que é considerado o primeiro contato entre o organismo e o meio ambiente, alguns conceitos básicos são apresentados a seguir (Coren et al, 1979).

Processo Informativo - O processo informativo, descreve o comportamento, assumindo que a maneira com que o observador processa a informação inclui uma fase de registro ou sensorial, uma fase de interpretação e uma fase cognitiva ou de memorização. A 
cognição é um termo usado em psicologia ligado ao aprendizado e utilizado para fazer referências à memória, associações, linguagens e soluções de problemas, como também para alguns investigadores inclui os processos de atenção e a representação consciente. Em outras palavras, cognição tende a estar em algum lugar entre áreas tradicionalmente chamadas de percepção e aprendizado, e incorpora elementos de ambos. Porém, nenhum desses termos ou abordagens pode ser considerado como áreas distintas de estudo, pois, desde o primeiro registro de estímulo no receptor até a representação consciente final na memória deve-se analisar sistematicamente.

Detecção - O problema básico para qualquer sistema sensorial é detectar a mudança de energia presente no meio, que pode ocorrer através de um estímulo na forma de luz, de som, química ou mecânica. A detecção gira em torno do problema em dizer o quanto de estímulo, em relação ao nível zero de energia, é necessário para o indivíduo dizer que o escuta, enxerga ou sente. A maneira utilizada para medir esse limite irá variar com o foco da pesquisa. E esses limites variam freqüentemente, tanto por influência de outros estímulos, muitas vezes impossíveis de serem anulados, quanto por erros humanos. Assim, é comum utilizar-se a média dos resultados encontrados. Tomando o som como exemplo, pode-se apresentar um tom que não seja audível para os seres humanos e ir aumentando-o gradativamente, até que o indivíduo em teste diga que consegue escutá-lo. Ou, ao contrário, fazê-lo escutar um som qualquer e ir diminuindo-o, até que não seja mais possível escutá-lo. Utilizam-se ainda níveis de sons controlados ao fundo, para que o processo tenha mais constantes definidas e o indivíduo tenha uma idéia do nível do ruído com o qual o estímulo irá competir. Classes de estímulos perceptíveis e outras de estímulos não perceptíveis também podem ser apresentadas, alternadamente ou numa ordem pré-estabelecida, e o observador deverá dizer se as percebe ou não. Entretanto, como muitas vezes, o indivíduo testado, para parecer mais sensível, responde que percebe o estímulo mesmo não o tendo feito, criou-se a Teoria do Sinal Detectado. Desta maneira, não se estuda apenas a capacidade do observador em detectar um estímulo, mas, sua habilidade para analisar o quão seguro está de que sua resposta não está sofrendo influência de erros comuns, como de perseverança e antecipação Quando o sinal está ausente, o sistema sensorial do observador ainda está em atividade, gerando outros sinais que variam a cada momento. Essa flutuação no nível do sinal é provavelmente causada por processos fisiológicos, de atenção e outras variáveis ligadas ao sistema de percepção do observador. Algumas vezes, a sensação de estar realmente sentindo o sinal é tão intensa quanto o próprio sinal. Vemos assim que, tanto a motivação, quanto a expectativa do 
observador, afetam as respostas durante o experimento de detecção (Coren et al, 1979).

Reconhecimento - Muitas vezes, detectar um sinal não é um problema, pois, este está bem acima do limite de detecção. Entretanto, reconhecê-lo ou identificá-lo, não é uma tarefa simples. A dificuldade depende em parte do número de estímulos alternativos possíveis de ocorrer em relação ao que o observador deverá distinguir. O nível de complexidade do sinal emitido e a habilidade do sistema sensorial do observador para transmitir e decodificar no sistema nervoso central este sinal indicará o grau de identificação do estímulo. O reconhecimento do sinal requer mais informações a respeito do estímulo do que as necessárias para sua detecção (Coren et al, 1979).

Discriminação - O problema da discriminação é saber se um estímulo é diferente de um outro, e o quanto um estímulo é diferente de outro a ponto de não serem o mesmo. Para isso, devem-se fornecer especificações adicionais ao problema. Utiliza-se um estímulo padrão e variações em uma única dimensão, para estabelecermos assim o limite de diferença entre o padrão e o estímulo. № caso da exposição prolongada de um estímulo de cor também há modificações na percepção da nuance. O brilho de um estímulo pode ser afetado pela intensidade do estímulo adjacente. A natureza inibitória desta interação faz com que uma redondeza muito brilhante escureça o alvo. Esse tipo de interação também pode ocorrer entre sistemas de cores adjacentes, alterando os resultados das nuances. O fenômeno é chamado de Contraste Simultâneo de Cor. O mecanismo é similar à adaptação cromática, exceto pelo fato de que aqui temos uma resposta neural instantânea, enquanto que no segundo caso o efeito é de fadiga devido ao Efeito Purkinje. O Efeito Purkinje consiste em: "A visão fotópica tem sua máxima sensibilidade para o amarelo, a visão escotópica tem a máxima sensibilidade para o azul, este deslocamento, denominado "Efeito Purkinje", faz com que cores que aparentemente são mais claras na visão fotópica, por exemplo, laranja x verde, tenham uma aparência contrária quando o nível luminoso chega ao âmbito do escotópico; isto é, o que antes parecia como claro tornar-se-á escuro". Mas, nas duas situações percebemos a nuance de cores complementares do estímulo produzido, que serão vistas no item referente à classificação de cores.

A visão, que engloba a percepção da cor, é algo em geral tão rápido e seguro, tão fidedigno e informativo, e supostamente ocorre tão naturalmente, que presumimos que ela é, de fato, algo que não necessita de esforço. Mas, a facilidade veloz da visão, é ilusória. Por trás da facilidade veloz da visão está uma inteligência tão extensa que ocupa quase metade do córtex cerebral. A visão não é meramente um produto da percepção passiva, ela é um 
processo inteligente de construção ativa (Hoffman, 2001). Neste contexto a percepção e utilização da cor deve considerar fundamentalmente os aspectos de construção ativa realizado pelo ser humano.

\section{4- ILUMINANTES}

É possível sentir a presença da luz antes mesmo de haver energia suficiente para discernirmos formas. A visão depende da presença de luz, e muitas percepções primitivas da visão são simples reações à intensidade da energia captada. Basicamente existem duas maneiras da luz alcançar os olhos: diretamente, a partir da radiação de uma fonte luminosa ou pela reflexão da energia radiante incidente numa superfície. A quantidade de energia proveniente de uma fonte luminosa é chamada de fluxo luminoso (lumens) e a quantidade de luz incidente numa superfície é chamada de iluminamento (lux). A relação entre a luz incidente numa superfície e a quantidade refletida é chamada de índice de reflexão da superfície (adimensional) (Costa, 1998) (Lida, 1995) (Coren et al, 1979) (Philips, 2000).

A cor não tem existência material, sendo resultado da sensação produzida nos órgãos sensores da retina, sob o efeito das radiações. Ao diminuir a iluminação constata-se que os objetos "perdem" a cor na seguinte ordem: vermelho, amarelo, verde e azul.

Quanto maior a iluminação, maior a acuidade visual, sendo possível identificar menores optótipos. A iluminação exagerada chega ao ponto de degradar a visão e até mesmo produzir lesão. Optótipo demasiadamente iluminado pode ser mais difícil de ser observado do que quando menos iluminado. Um aumento rápido de iluminação, quando o olho está adaptado à baixa luminosidade, pode provocar redução da acuidade visual. Para cada condição de adaptação existe um nível ótimo de iluminação. Quando o contraste relativo é reduzido, a intensidade luminosa tem de ser aumentada para manter a acuidade. Quanto maior o contraste, mais nitidamente o estímulo será percebido. Teoricamente, o contraste máximo é representado pela condição onde o estímulo está com a iluminação máxima, e a região adjacente com iluminação zero. É uma condição quase nunca encontrada na prática. A redução da iluminação causa baixa visual, ao nível em que começa o funcionamento dos bastonetes parafoveais e periféricos. A maioria das atividades da vida moderna é realizada com iluminação artificial, ao limiar do estímulo dos cones, ou seja, em visão fotópica.

Um dos principais fatores que influenciam a visão noturna é o contraste. Os objetos são vistos à noite mais claros ou escuros do que o ambiente em que se encontram, devido ao 
contraste. Este fato é de grande importância para os que se dedicam ao trabalho noturno, especialmente os motoristas e aviadores. Diferenças de contrastes são usadas pelos pilotos para descoberta de aviões inimigos, enquanto escondem suas próprias aeronaves. Ao voar sobre áreas escuras, como a terra, os pilotos devem voar abaixo do inimigo, quando sob luz branca (deserto e área iluminada) devem voar acima do inimigo.

A redução da iluminação influi no ponto próximo, de tal modo que, em visão escotópica o indivíduo possui apenas a metade da sua amplitude de acomodação. Haverá também redução do senso de profundidade que corresponde apenas a um décimo do encontrado em visão fotópica. Ocorrem então, distúrbios relativos à distância dos objetos que aparecem mais separados entre si do que realmente o são. Este fato é muito importante em condições de tráfego como, por exemplo, em caso de neblina, quando o veículo aparece mais afastado do que na realidade. Superfície branca em contraste com um fundo escuro aparece menor e mais distante do que a superfície escura sobre o fundo branco (Alves, 1999). Atualmente, as lâmpadas elétricas podem ser divididas em dois grupos principais: as lâmpadas incandescentes e as lâmpadas de descarga.

As lâmpadas incandescentes produzem luz pelo aquecimento elétrico de um filamento a uma temperatura tão alta, que a radiação emitida cai na região visível do espectro eletromagnético. As principais partes deste tipo de lâmpada são, filamento, bulbo, gás e base (soco). Quanto mais elevada for a temperatura do filamento, maior será a proporção da energia radiada que corresponde à região visível do espectro e maior será a eficácia da lâmpada. Nas lâmpadas modernas, o filamento utilizado é de tungstênio, que tem ponto de fusão elevado e velocidade de evaporação baixa, permitindo maiores temperaturas de operação e, conseqüentemente, maiores eficácias luminosas. Um outro método para aumentar a eficácia luminosa é o de espiralar o filamento, que apresentará uma superfície efetiva menor para o gás, e reduzida perda de calor por condução e convecção. O filamento duplamente espiralado aumenta ainda mais a eficácia e diminui o tamanho deste. O bulbo normalmente é de vidro, sendo fechado, o quê impede que o filamento entre em contato com o ar externo, cujo oxigênio provocaria a queima imediata da lâmpada. Ele pode ter várias cores, mas, se obtém maior difusão de luz quando se reveste o interior deste com uma fina camada de silicato branco. O gás inerte que preenche o bulbo, reduz a evaporação do filamento, permitindo um aumento da temperatura que trabalha o filamento. Os gases mais usados são nitrogênio e argônio. Quanto maior a pressão do gás, tanto menor será a evaporação do filamento e maior será a eficácia luminosa e a vida da lâmpada. E a base ou soco é a parte 
condutora da lâmpada, feita em metal, que a ligará ao receptáculo. Os metais mais usados são latão, alumínio e níquel. Elas são identificadas pela letra E, quando forem de rosca, ou pela letra $\mathrm{B}$, de baioneta, seguidas por um número que indica o seu diâmetro em milímetros.

Dentre as lâmpadas incandescentes existem dois tipos especiais: as lâmpadas refletoras e as hampadas halógenas. As lâmpadas refletoras dirigem a luz produzida em uma direção predeterminada, pois possuem uma fina camada metálica depositada na superfície interna do bulbo, funcionando como espelho. Existem principalmente dois tipos: A lâmpada de vidro prensado (vidro duro resistente ao calor), desenhada para fachos de luz em diferentes aberturas - estreitas (spot), ampla (flood) e muito ampla (wide flood). Estas lâmpadas resistem bem aos choques térmicos e podem ser usadas ao ar livre sem proteção. E a lâmpada de vidro "soprado". Neste tipo de lâmpada a parte frontal é de cristal esmerilhado. Também fabricadas como as de vidro prensado para diferentes fachos de luz, neste caso, a abertura do facho será determinada pela posição do filamento em relação ao espelho, e em cores, porém a intensidade luminosa destas lâmpadas é menor que a anterior de mesma potência. Têm a vantagem de serem menores e mais leves, sendo ideais para iluminação de interiores. Um terceiro grupo de lâmpadas refletoras possui o refletor interno situado na parte esférica do bulbo, essas lâmpadas são usadas em combinação com um refletor separado para se obter a distribuição de luz desejada.

As lâmpadas incandescentes normais provocam evaporação de partículas de tungstênio e posterior condensação na parede interna do bulbo com conseqüente enegrecimento do mesmo. Para que isto não ocorra, agrega-se ao gás normal um elemento químico da família dos halógenos (iodo, flúor, bromo), estabelecendo-se um ciclo de regeneração do tungstênio, impedindo o escurecimento do bulbo. Essas lâmpadas, conhecidas como halógenas, são fabricadas em cristal de quartzo, que resistem às altas temperaturas em que ocorre a regeneração do tungstênio. São usadas em iluminação por projeção, projetores de cinema e faróis de automóveis, por exemplo.

Tanto a vida de uma lâmpada, quanto seu fluxo luminoso, são determinados pela temperatura do filamento. Quanto maior a temperatura para uma dada lâmpada, maior a sua eficácia (lumens emitidos por watt) e menor a sua vida. Qualquer variação na voltagem aplicada numa lâmpada incandescente causa uma modificação nas suas características de funcionamento. Esta relação entre as características de funcionamento e voltagem é mostrada nas figuras 4.1 e 4.2 : 

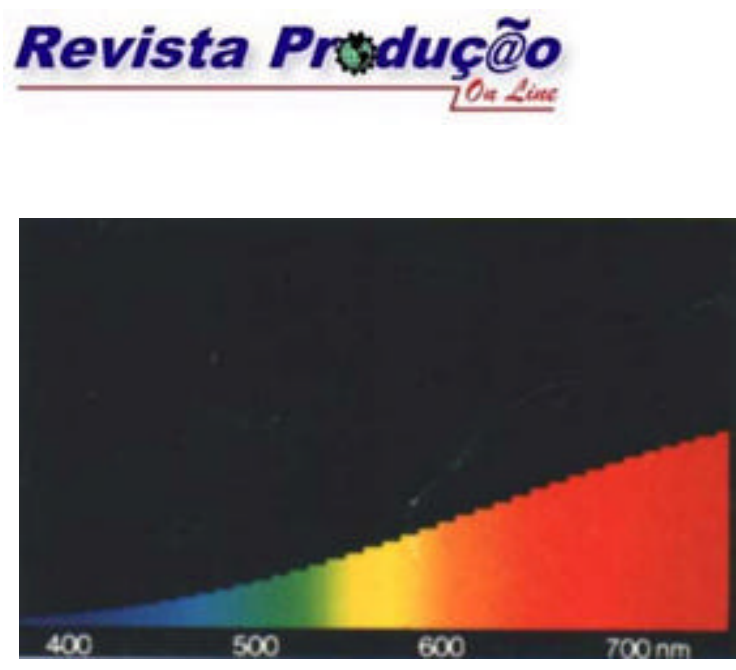

lâmpada incandescente

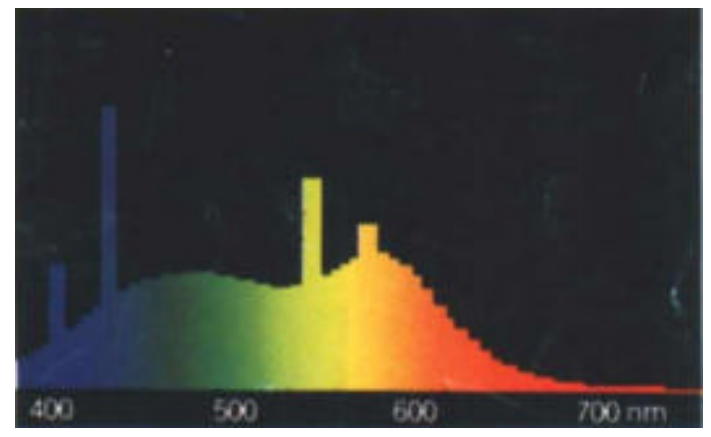

fluorescente luz do dia

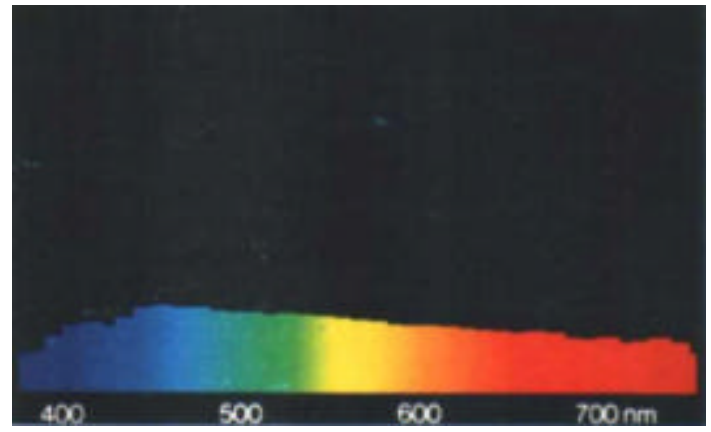

radiação solar

Figura 4.1 - Espectros para simulação e espectro solar.

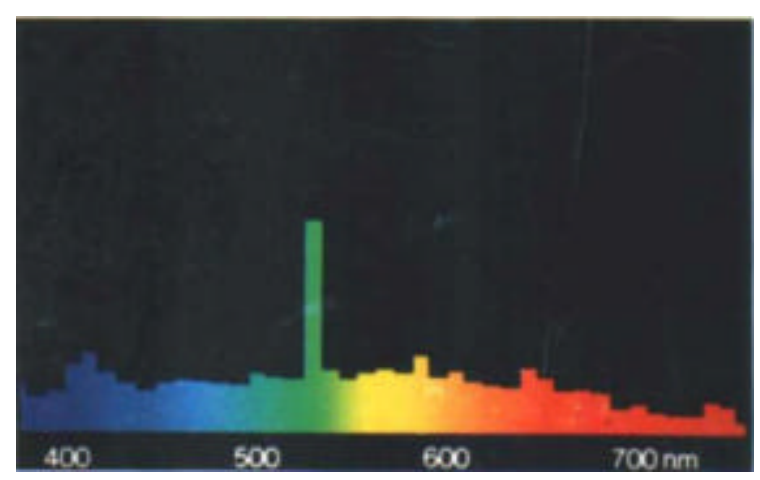

multi-vapor metálico

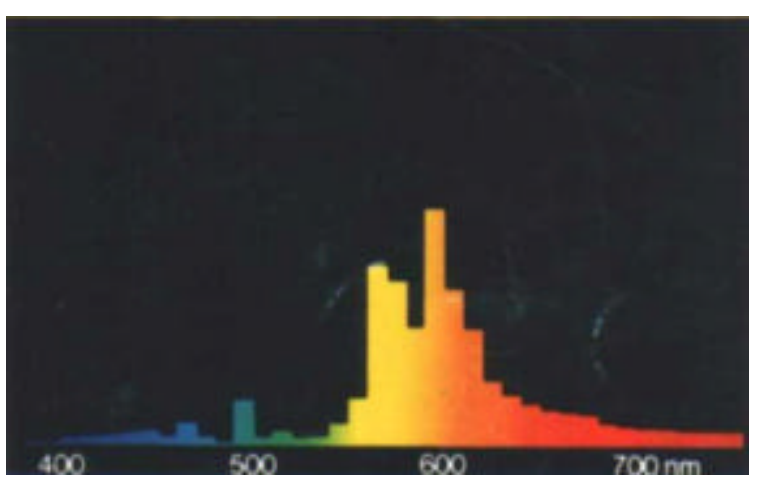

vapor de sódio

Figura 4.2 - Espectro de iluminação pública e industrial.

Nas lâmpadas de descarga, a luz é produzida não por aquecimento de um filamento, mas por descarga elétrica num gás ou vapor ionizado, algumas vezes há a combinação de luminescência dos compostos de fósforo excitados pela radiação gerada com descarga elétrica. Existem vários tipos de tubos de descarga, bem como são usados diferentes gases. Nas lâmpadas fluorescentes tubulares mais usadas, o tubo de descarga tem a forma cilíndrica. A superfície interna do tubo é recoberta com o pó fluorescente, cuja composição determina a cor e a quantidade de luz. São fabricadas com potência de 4 a 215 watts. Possuem alta eficácia luminosa, mas sua radiação é quase monocromática. São usadas quando a reprodução de cores 
não é muito importante, mas sim a percepção de contrastes, por exemplo, em autopistas. Para efeito de comparação entre a eficiência luminosa de uma lâmpada incandescente de tungstênio e a de uma lâmpada fluorescente comum, tem-se para uma lâmpada incandescente de $100 \mathrm{~W}$ de potência a emissão de aproximadamente $1700 \mathrm{~lm}$. Ou seja, a sua eficiência luminosa está entre 15 e 20 lm/W (1700lm/100 W=17lm/W). Já uma lâmpada fluorescente de $40 \mathrm{~W}$ emite aproximadamente $2100 \mathrm{~lm}$, sendo a sua eficiência luminosa de $50 \mathrm{~lm} / \mathrm{W}$.

Um lançamento recente é o das lâmpadas fluorescentes compactas que duram 10000 horas. Uma destas lâmpadas de $20 \mathrm{~W}$ tem a mesma eficiência luminosa que uma lâmpada incandescente de $75 \mathrm{~W}$ e ainda tem uma durabilidade dez vezes maior, com menor consumo de energia.

Em relação às lâmpadas fluorescentes, pensoutse durante muito tempo que uma boa reprodução de cor somente poderia ser obtida a custo da eficiência e fazendo-se a fonte radiar a gama de cores completa do espectro visual. Sabe-se, agora, que isto não é necessariamente o caso, e existem lâmpadas fluorescentes, cuja emissão se concentra em três comprimentos de onda muito bem definidos para dar uma boa reprodução de cor combinada à alta eficiência.

A reprodução de cores era igual em qualquer ambiente quando a iluminação era exclusivamente incandescente, mas, com a introdução de novas fontes luminosas, foi necessário adotar um índice baseado na iluminação incandescente padrão. $O$ índice de reprodução de cor (IRC) é obtido através da comparação de um número de cores de referência (8 a 14 dependendo da precisão requerida) sob a luz da amostra e do iluminamento de referência, sendo calculado seus desvios relativos. Quanto menor o desvio, mais próximo de 100 estará a amostra em relação ao iluminante de referência, ou seja, um índice 100 corresponde a uma reprodução de cor similar a que seria produzida por uma lâmpada incandescente, um índice 65, corresponde a 65\% de reprodução de cores de uma lâmpada incandescente (Philips, 2000) (Alves, 1999).

\section{5- SEGURANÇA INDUSTRIAL}

O objetivo da maior parte das profissões existentes é o de solucionar problemas advindos da natureza ou os que o próprio homem cria. Os profissionais ligados à área de iluminação são um bom exemplo a ser dado, pois a luz, tanto natural, como artificial, além de representarem a proteção e a segurança, permitem a adaptação do trabalho em ambientes escuros. Desta forma, ao longo da história da humanidade a iluminação tem um crescimento 
contínuo, e mais acentuado ainda quando o homem começa a fazer a substituição da fadiga dos músculos pelas máquinas. Mas, para a adequação do homem às máquinas, a fadiga passou então a ser um fato constante no sistema visual, e o estudo científico da iluminação tornou-se essencial. Desta forma, os fabricantes, os pesquisadores e as universidades estabeleceram os objetivos principais de um sistema de iluminação, tais como, a reprodução de cores, intensidade luminosa, distribuição e direção das luzes e economia energética. (Costa, 1998)

Hoje, o sistema de iluminação é composto por dois ramos da ciência que se completam, o da produção da luz e o da utilização da luz, e que englobam diversos fatores, que podem ser representados pelo esquema apresentado na figura 5.1.

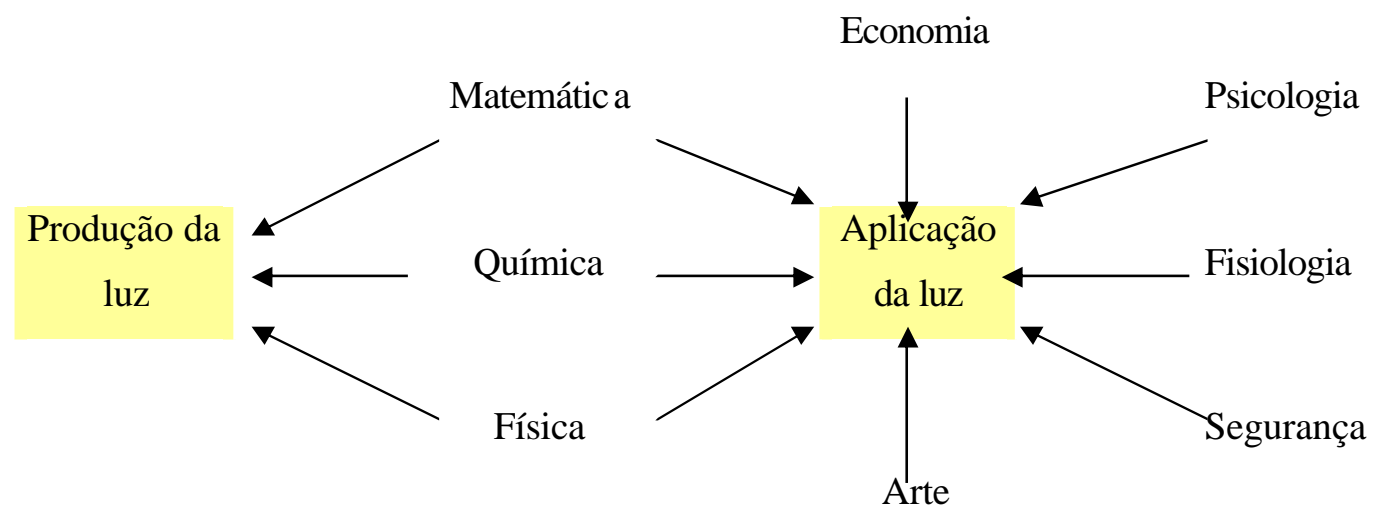

Figura 5.1 - Sistema de iluminação.

A Consolidação das Leis do Trabalho, também conhecida como CLT, no Capítulo V relativo à Segurança e Medicina do Trabalho, Seção VII, art. 175, menciona que "em todos os locais de trabalho deverá haver iluminação adequada, natural ou artificial, apropriada à natureza da atividade". Na mesma seção os parágrafos primeiro e segundo referem-se à quantidade e qualidade da iluminação, mencionando que o Ministério do Trabalho estabelecerá os valores mínimos a serem observados. Porém, até bem pouco tempo atrás, estes valores mínimos entravam em contradição com a própria $\mathrm{ABNT}$, visto que havia uma duplicidade de níveis: um estabelecido pela CLT e o outro pela NBR 5413. O problema era mais ou menos grave, pois os valores preconizados pela CLT eram mais elevados que os da ABNT. A razão para o fato é que esta última, com base na experiência de outros países mais avançados, começou a adotar níveis compatíveis com o rumo de novos tempos economizadores de energia. Os valores mínimos, mencionados pela Norma, devem levar em conta o caráter psicofisiológico da visão e indicam a iluminância mínima necessária para se 
perceber um detalhe de dimensões dadas e bem contrastadas, sem intervir na noção de objetos no campo visual."

No Brasil, os projetos de sistema de iluminação ainda contam com as seguintes normas técnicas relativa às cores de cilindros, tubulações e condutores:

Tabela 5.1 - Normas técnicas.

\begin{tabular}{|l|l|}
\hline NORMA & \multicolumn{1}{|c|}{ ASSUNTO } \\
\hline NBR 7195 & Cores para segurança \\
\hline NBR 8421 & Identificação por cores das tubulações em instalações industriais \\
\hline NBR 8663 & Identificação de cores para condutores elétricos nus e isolados \\
\hline NBR 12176 & Cores para cilindros \\
\hline NBR 13193 & Cores para cilindros armazenadores de gases industriais \\
\hline
\end{tabular}

As indústrias lidam com riscos de acidentes que requerem avisos de advertência com bastante freqüência. Milhares de pessoas morrem ou sofrem acidentes porque avisos de advertência não estão presentes, não são adequados ou simplesmente não foram notados. Assim, um problema significativo faceando a ergonomia e profissionais da área de segurança, tem sido como advertir o público dos perigos apresentados pelos produtos ou por sua utilização inadequada. Os avisos são essencialmente instruções advertindo a presença de perigos e como evitá-los. Vários formatos padronizados são utilizados hoje em dia nas embalagens, rótulos e bulas de produtos. Os quatro itens geralmente tidos como essenciais para uma mensagem de advertência incluem: o sinal indicando a presença de um perigo, a natureza do perigo, as conseqüências ao se ignorar o aviso, e como evitar o perigo. Desta forma, cores e palavras têm sido utilizadas para que esses avisos sejam detectáveis pelo público alvo (Griffith e Leonard, 1997) (Leonard, 1997).

Entretanto, pouca atenção tem sido dada à eficiência das cores como sinais, e na realidade, utilizar correspondências entre cores e a severidade do perigo, poderia ser a chave para tais problemas. Abordagens alternativas são sugeridas. Isto inclui componentes de forma como parte do sinal, e a necessidade de treinamento para os indivíduos sobre a natureza dos sinais de advertência. Símbolos, como a negação de um ferimento, também são utilizados para acrescentar um sinal. Em adição ao papel de atrair a atenção, sinais têm sido apresentados como guias indicando o nível do risco envolvido em um perigo. Padrões de 
cores utilizados atualmente para serem associados a diferentes níveis de perigo, não são baseados em estudos empíricos (Griffith e Leonard, 1997) (De Turck, 1991).

Algumas experiências lidam com a associação de cores componentes de um sinal com as palavras deste sinal. As cores sugeridas por várias organizações não estão em consonância com os dados dessas experiências, assim como as sugeridas para cilindros de gases. Palavras e cores como perigo e vermelho, são freqüentemente utilizadas em conjunto para atrair atenção. Alguns desses pares palavra/cor componentes de guias utilizados pelas indústrias (como os guias da Westinghouse), como Perigo/Vermelho, Cuidado/Laranja, Atenção/Amarelo e Observe/Azul, não produzem as reações esperadas. Apesar de em alguns estudos ter sido encontrada alguma correspondência entre as palavras de um sinal e a severidade presumida das consequiências de um determinado perigo, a força desta relação não tem sido grande (Wetinghouse, 1981) (Underwood et al, 1962).

Segundo S. David Leonard, pouco suporte empírico para esses padrões, especialmente envolvendo cores, foi encontrado por deTurck et al. Eles argumentaram que as quatro cores (vermelho, laranja, amarelo e azul) não correspondiam naturalmente ou inerentemente aos níveis de riscos especificados. E apesar disso, a combinação cor-palavra é vastamente utilizada nas indústrias. Mas, essa pode não ser uma prática efetiva. Freqüientemente, essas combinações incluem dois estímulos, mas, a atenção pode ser direcionada para apenas um deles. A notabilidade relativa do estímulo foi sugerida como sendo a explicação para o bloqueio ou ofuscamento em estudos realizados por Rescorla e Wagner. Seus trabalhos sugeriram que a introdução de um estímulo adicional num estágio avançado de aprendizado produz pequena ou nenhuma associação deste estímulo adicionado com o já existente; o reconhecimento de um perigo pode tomar o lugar de um estímulo incondicional, em associações entre sinais e seus contingentes (Leonard, 1997).

Projetistas insistem que certas palavras, cores ou símbolos, ou suas combinações podem levar a conclusões abstratas (nível de riscos) que são bem diferentes das utilizadas normalmente. E mais, a necessidade de se estar ciente de níveis de risco deve ser assumida pelos provedores destes avisos como primordial para usuários sem treinamento ou prática. Chapanis estudou a percepção do risco associada com as palavras perigo, cuidado e atenção com os efeitos das quatro cores, branco, amarelo, laranja e vermelho, e achou que a única resultante realmente forte foi a combinação perigo-vermelho, que era associada com o maior nível de risco. A percepção do risco associada com outras palavras de sinais era inconsistente. E mais, outras combinações de cores e palavras foram tão misturadas, que nenhuma 
recomendação foi oferecida, exceto que, em geral, qualquer cor era melhor que branco (Goldhaber e De Turck, 1988).

Estudos recentes avaliaram a interação entre palavras, cores e a legibilidade do caracter na percepção do nível do risco. A conclusão foi a de que o vermelho era o único indicador consistente de risco.

Participantes do sexo feminino, selecionados por constituírem um grupo altamente preocupado com produtos de segurança, e cujo índice de incapacidade para percepção de cores é menor que $1 \%$, demonstrou através de suas respostas que a cor vermelha era dada como resposta dominante em todos os contextos, exceto quando apareciam palavras como fatal ou venenoso, onde a cor preta era a escolhida. As mulheres geralmente menos envolvidas em ocupações que exijam treinamento sobre os efeitos de certos acidentes, (por exemplo, transporte de cargas), e mesmo demonstrando maior sensibilidade em relação às variações de nuances que os homens, provaram que a forte associação do vermelho com todas as palavras padrões. Os resultados mostraram que existe pouca associação entre as palavras e as cores (Griffith e Leonard, 1997).

De todos os experimentos analisados neste estudo, conclui-se que a utilização limitada das cores para conotação de riscos relativos é uma realidade freqüente nas indústrias. Tais estudos sugerem que o ranking relativo das cores concorda em grande parte com aquele utilizado pelos padrões típicos, e que as palavras também são arranjadas numa ordem similar, entretanto, os dados indicam que não há associação real entre cores e palavras utilizadas em padrões, exceto com o vermelho. E mais, a perfeita associação do vermelho com a palavra "pare" sugere a forte influência dos sinais de trânsito no público em geral, e a transferência positiva do risco associado à cor vermelha.

Desta maneira, os resultados obtidos através desta pesquisa podem ser mais que uma ferramenta de estudo, mas, uma necessidade para as indústrias de todos os segmentos (Griffith e Leonard, 1997).

\section{6- CONCLUSÕES}

Sendo a cor o atributo mais evidente de um produto, a qualidade deste retrata-se inicialmente na fidelidade da cor. As tolerâncias admissíveis na diferença de cor, obrigam a cuidados na formulação da cor, com implicações nos aspectos de reprodutibilidade, estabilidade e longo período de envelhecimento. Porém, como as condições de iluminação e 
observação dos produtos são variáveis, impõe-se uma redução dos efeitos metaméricos. E se a cor é componente do produto industrial, também é importante na organização do ambiente da produção industrial. A cor afeta a atividade humana, ao nível psicológico e fisiológico, com reflexos na atividade do córtex, do sistema nervoso reflexivo e atividade hormonal. A cor influência o estado emocional, as impressões objetivas, subjetivas e o próprio estado de espírito. A cor afeta a percepção que se tem de volume, peso, temperatura, tempo, odores e ruídos.

Por isso, a cor deve ser considerada em termos ergonômicos e de segurança, no quadro da arquitetura e desenho de ambientes industriais (Dos Santos, 2003). Além do nível de iluminação correto, a cor deve proporcionar um ambiente que contrarie a fadiga prematura (nesse caso, a o controle de contrastes de luminância e complementaridade de cores - redução de pós-imagem/vide figura 2.16), é fundamental, reduza o stress, minimize erros e contribua para a orientação, equilíbrio e segurança. Cada caso deve ser objeto de estudo particular, levando-se em consideração as operações e equipamentos empregados, as características dos produtos, o tipo de iluminação e as dimensões da planta industrial (Kwallek e Lewis, 1990) (Soares, 1993).

Além do nível de iluminação correto, a cor deve proporcionar um ambiente que contrarie a fadiga prematura (nesse caso, o controle de contrastes de luminância e complementaridade de cores - redução de pós-imagem), é fundamental, reduza o stress, minimize erros e contribua para a orientação, equilíbrio e segurança. Cada caso deve ser objeto de estudo particular, levando-se em consideração as operações e equipamentos empregados, as características dos produtos, o tipo de iluminação e as dimensões da planta industrial (Kwallek e Lewis, 1990) (Soares, 1993).

Pela importância científica, tecnológica, industrial e econômica, a cor tem que ser gerida quantitativamente e aceita globalmente (Dos Santos, 2003). A gestão é um conjunto de ciências com vista a melhorar os sistemas sociais através de métodos científicos, a gestão quantitativa da cor conduz à metrologia da cor (colorimetria, ou ainda espectrocolorimetria). O método de definição da aparência de cor da CIE (Comissão Internacional de Iluminação) com base num modelo matemático, se inspira nas observações experimentais de diferenças de cor. A tecnologia teve que desenvolver capacidades para a manipulação da cor. A eletrotécnica, o tratamento informatizado, a aquisição, o processamento e a reprodução de imagens, enfrentam desafios de manipulação da cor, no sentido de se obterem soluções compatíveis com o grau de diferenciação que a visão colorida possui (Soares, 1993). 


\section{7- AGRADECIMENTOS}

À FAPERJ (Projeto Temático: Metrologia baseada em Visão Computacional) pelo apoio financeiro. Aos Engenheiros Públio Lima de Mello (GE do Brasil Ltda) e Salomão Miguel Jabbour (Inmetro), pela troca de idéias no âmbito de normas técnicas. Ao Prof. Dr. João Carlos Soares de Mello (UFF) pelas importantes intervenções nas nossas discussões científicas e a Alain Rangel, técnico do LMDC (Laboratório de Metrologia Dimensional e Computacional da UFF), pelo apoio na realização dos experimentos que substanciaram este artigo.

\section{8- REFERÊNCIAS BIBLIOGRÁFICAS}

ALVES, Aderbal Albuquerque. Refração. 3 ed., Rio de Janeiro, Editora Cultura Médica, 1999.

COREN, Stanley; PORAC, Clare; WARD, Lawrence. Sensation and Perception. New York, Academic Press, 1979.

COSTA, G. J. C. Iluminação econômica: Cálculo e avaliação. Porto Alegre, EDIPUCRS, 1998.

DE TURCK, M. A.; GOLDHABER, G. M.; RICHETTO, G Uncertninty reduction in product warnings: effects of fear and color. Journal of Products Liability, v. 13, p. 339-346, 1991.

DOS SANTOS, A. R. M., Percepção de Cores em Ambientes Industriais, Dissertação de Mestrado, Programa de Pós-Graduação em Engenharia Mecânica, UFF, Niterói, 2003.

GOLDHABER, G. M.; DE TURCK, M. A. A dimensional analysis of signal words. Forensic Reports, 1: p 193-206, 1988.

GRIFFITH, L.J.; LEONARD, S.D. Association of colors with warning signal words. International Journal of Industrial Ergonomics, v. 20, p. 317-325, 1997.

HOFFMAN, Donald. Inteligência visual: Como criamos o que vemos. Rio de Janeiro, Editora Campus, 2001.

KWALLEK, N.; LEWIS, C.M. Effects of environmental colour on males and females : A red or white or green office. Applied Ergonomics, v. 21, n. 4, p. 275 - 278, 1990.

LEONARD, S. D. Does color of warnings affect risk perception? International Journal of Industrial Ergonomics, v. 23, p. 499-504, 1997. 
LIDA, Itiro. Ergonomia: Projeto e produção. 3 ed., São Paulo, Editora Edgard Blücher ltda., 1995.

PHILIPS. MANUAL DE ILUMINAÇÃO PHILIPS. Rio de Janeiro, p. 10-25, p. 239-253, 2000 .

SOARES, O. D. D. A Gestão da cor pelo homo color. Portugal, Editora CETO, 1993.

UNDERWOOD, V. J.; HAM, M.; EKSTRAND, B Cue selection in paired associate learning. Journal of Experimental Psychology, v. 64: p 405-409, 1962.

WESTINGHOUSE ELETRIC CORPORATION Product Safety Label Handbook. Westinghouse Printing Division, 1981. 